Original article

\title{
Impact of Using Suprapubic Cystostomy during Monopolar Transurethral Resection of Large Size Prostate: A Prospective Study
}

\author{
Abd Elrahman Mahmoud Elfayomy ${ }^{1}$, Khaled Mohamed Abd Elsamad ${ }^{1}$, Esam abdelmohsen \\ Desoky ${ }^{l}$ and Abdulmonam Emhemmed forgani ${ }^{*}$ \\ ${ }^{1}$ Egypt, Zagazig University, Faculty of Medicine, Urology Department \\ ${ }^{2}$ Libya, Tripoli University, Faculty of Medicine, Urology Department
}

*Corresponding author:

Abdulmonam Emhemmed Forgani abdulmonamalforgany@gmail.com

$\begin{array}{ll}\text { Submit Date } & 2019-03-20 \\ \text { Revise Date } & 2019-05-07 \\ \text { Accept Date } & 2019-05-11\end{array}$

\begin{abstract}
Background: Benign prostatic hyperplasia (BPH), the most common benign neoplasm in men. Despite the development of medical therapy and alternative minimally invasive procedures, the monopolar transurethral resection of the prostate still the "gold standard" in the operative management of BPH . Purpose: To evaluate efficacy and safety of suprapubic cystostomy during resection of the prostate $>80$ gram. Patients and methods: In this study patients operated with monopolar TURP between January 2018 and January 2019 were evaluated at zagazig university hospital . During surgery a catheter (12 Fr) was placed suprapubically. All patients were followed-up for at least 6 months after surgery. Results: the mean age (64.95 \pm 4.43), IPSS $(\mathbf{2 8 . 8 1} \pm \mathbf{2 . 0 8})$, , and post void residual (PVR) 82.75 $\pm \mathbf{2 0 . 9}$. Mean prostate volume was $(\mathbf{8 8 . 8 7} \pm \mathbf{7 . 5}) \mathrm{g}$. mean surgical time was $(47.5 \pm 7.03) / \mathrm{min}$, mean catheter time removed was( $2.37 \pm 0.44)$ day, mean post operative hospital stay was $(2.38 \pm 0.46)$ day, mean bladder pressure was $(11.83$ $\pm 0.44) \mathrm{cmH} 2$, mean percentage of resection to prostate $\operatorname{size}(0.60 \pm 0.08)$ and the mean Resection efficiency was $(1.14 \pm 0.23) \mathrm{g}$ /mint. Blood transfusion was not necessary and developed TUR syndrome (0.0). At follow-up the mean IPSS (3.55 \pm 1.), and PVR (18.79 \pm 7.27). regard late complication (16cases) $66.7 \%$ were without any complication $29.2 \%$ with retrograde ejaculation and 1 case $4.2 \%$ was with incontinence. Conclusion: we can conclude the using of suprapubic cystostomy during monopolar transurethral resection of large prostate $>80$ gram, is more safe and more effective method .
\end{abstract}

Keywords: suprapubic cystostomy, Monopolar Transurethral Resection, Large Size Prostate

\section{INTRODUCTION}

$B^{\text {sin }}$ $\mathrm{PH}$ is clinically characterized by lower urinary tract symptoms and can cause urinary retention, hematuria, urinary tract infection (UTI), bladder calculi, or dilation of the upper urinary tract with or without renal insufficiency[1]. Patients For prostates $>80$ cc, the EAU guide-lines recommend open prostatectomy or laser enucleation. Published studies report that TURP is associated with higher complication rates when performed in larger glands, in particular regarding blood transfusion and TUR syndrome [2]
The theoretical risk factors for TUR syndrome include a high irrigation pressure, patent prostatic sinuses, prolonged surgical time, and the application of hypotonic irrigation fluid [3]. A resection time of $>90$ min, estimated prostate weight $>45 \mathrm{~g}$, age $>80$ years, acute urinary retention, and African descent are associated with increased morbidity[4]

We have carried out standardized monopolar TURP using a suprapubic cystostomy This study's objective was to ensure this method more safe and more 
effective by asses the operative complications and long-term patient outcomes after surgery in patients with glands $>80 \mathrm{gm}$

\section{AIM OF THE WORK}

The aim of this study was to ensure the patients have large size prostate and received M-TURP with suprapubic cystostomy during operation is more safe and more effective method.

\section{PATIENTS AND METHODS}

This is a prospective study carried out at the department of urology, Zagazig university hospitals from January 2018 to January 2019. assuming that rate of admission of patients with large size prostate $>80 \mathrm{gm}$ at urology department. So, sample size was calculated by open Source Epidemiologic Statistics for Public Health EPI to be 24 cases with power level $80 \%$ and confidence level $95 \%$. The primary endpoint is Benign prostatic obstruction removed, safety for the patients and secondary end point resection efficacy, intra and postoperative complications .

This study was done on 24 patients schedule for TURP, absolute indication for active intervention for BPH Bothersome urinary tract symptoms not responding to medical therapy with alpha blockers and Prostatic volume $\geq 80 \mathrm{gm}$. as measured by Trans rectal ultrasound (TRUS) . We excluded patients with Uncontrollable bleeding tendency, Patients with urethral stricture, Patients with bladder pathology (bladder tumor), Patients with history of urethral, bladder neck or prostatic surgery and prostate cancer was diagnosed preoperatively.

Patient evaluation was done by establishment of the inclusion criteria, History taking and with particular emphasis on urological history and Clinical evaluation of the patient regarding general condition abdominal and local examination of the external genitalia in addition to focused neurological examination ,Digital rectal examination, cardiological and anesthesia consultations were done .

Preoperative laboratory investigations were done including : Complete blood count, kidney function tests serum .creatinin , BUN", serum electrolytes [sodium],liver function tests, coagulation profile, Prostatic specific antigen [PSA], urine analysis and urine culture and sensitivity when needed .

Radiology: Pelvi-abdominal ultrasonography to assess post voiding residual urine (PVR), bladder pathology and Trans rectal ultrasound (TRUS) accurate estimation of the prostate size.

\section{Operational technique}

All patients (24) who undergone monopolar TURP were performed using the electrosurgical unit (KLS martin Me Mb1) the settings for cutting and coagulation. the cystourethroscopy was done to evaluate the urethra and exclude associated urethral pathology and to assess the size of the adenoma, to detect any bladder pathology and to identify the site of the ureteric orifices. Written informed consent was obtained from all patients and the study was approved by the research ethical committee of Faculty of Medicine, Zagazig University. The work has been carried out in accordance with The Code of Ethics of the World Medical Association (Declaration of Helsinki) for studies involving human.

The Surapubic cystostomy was done by $14 \mathrm{~F}$ suprapubic trocar and fixed nelton catheter size 12 FR introduced after filled of urinary bladder by irrigate glycine solution and under vision of cystoscopy . In our study, the steps of TURP resection were as follows : Before introduction of the resectoscope sheath, we used large amounts of lubricating jell around the sheath to prevent thermal damage to the urethra and to decrease the possible incidence of postoperative urethral stricture ,After introduction of the resectoscope into the bladder and before resection is started, the landmarks of the prostate were carefully reexamined which include the bladder neck proximally and the verumontanum distally are very important to prevent subtrigonal resection and ureteric orifices injury proximally or injury to the external sphincter distally which leads to total incontinence

We follow the Mauermayer technique. Resection in lobes(middle lobe and tissues latral to verumontanum , left Latral lobe, right lateral lobe and apical tissues last). Finally, reexamination of the prostatic fossa was done 
to secure final and adequate hemostasis and folly catheter $18 \mathrm{FR}$ was inserted and the balloon can be blocked in the bladder (40$50 \mathrm{cc})$ and put under traction to compress the fossa. This can done by traction of the catheter on the patient thigh.

The operation time during TURP was recorded from starting resection till urethral catheter fixation ,for more accurate resection efficacy and termination of the procedure before complete TURP (due to anesthetic or surgical cause)

\section{Postoperative follow up}

Bladder irrigation with normal saline $\mathrm{NaCl}$ (0.9) through suprapubic catheter and drained through the folly catheter, CBC and serum electrolyte was done on the $1^{\text {st }}$ postoperatively day to assess hemoglobin ,hematocrit and sodium for exclude blood or TUR syndrome and weight of resected prostate tissue folly catheter remove within 48 - 72 hours and patient did not go home until he voided in a satisfactory way with estimation of post voiding residual urine to ensure proper emptying.

Statistical analysis

Data were collected, tabulated and analyzed by SPSS 20, software for Windows. The significance level was set at $\mathrm{P}<0.05$.

\section{RESULTS}

This prospective study included (24) patients with Benign prostatic hyperplasia $(\mathrm{BPH})>80$ gram, presenting to Zagazig university Table (1):Age distribution among studied group $(\mathrm{N}=24)$ hospitals scheduled for transurethral resection of the prostate and follow-up period for 3 months . the results is tabulated in the following tables.

Table (1), showed that the mean age for the studied group was $(64.95 \pm 4.43)$ and range between 57-75 years. Table (2), showed that prostate size was distributed as $88.87 \pm 7.5$, PVR volume $82.75 \pm 20.9$, IPSS 26.12 \pm 3.67 , HB \& HT were $13.15 \pm 1.75 \& 47.04 \pm 1.89$ respectively and sodium in pre $138.66 \pm 1.92$. Table (3) showed that the mean operative time was $47.5 \pm 7.03$, mean pressure bladder was $11.83 \pm 2.46$ and mean resected tissue was 53.45 \pm 9.3 . Table (4), showed that the mean catheter time was $3.07 \pm 0.44$ and the mean of hospital stay was $2.38 \pm 0.4$. Table (5), showed that the mean postoperative prostate size was $34.7 \pm 7.3$, mean PVR volume 18.79 \pm 7.27 , mean IPSS $3.55 \pm 1.2, \mathrm{HB} \& \mathrm{HT}$ were $12.26 \pm 2.62 \& 46.41 \pm 2.01$ respectively and mean sodium value was $137.58 \pm 1.99$. Table (6), showed the Complication distribution among studied group, in which $54.2 \%$ without any early complication blood clot, hematuria and UTI were $12.5 \%$ each and incontinence one case with $8.3 \%$, regard late complication $66.7 \%$ were without any complication $29.2 \%$ with retrograde ejaculation and 1 case $4.2 \%$ was with incontinence. Table (7), showed that the mean resection efficiency $1.14 \pm 0.23$ and mean percentage of Resection to prostate size was $0.60 \pm 0.08$.

Mean \pm SD

\section{$64.95 \pm 4.43$}

Table (2):Preoperative data distribution among studied group

\begin{tabular}{|l|l|l|}
\hline Prostate size pre & Mean \pm SD & $88.87 \pm 7.5$ \\
\hline PVR volume pre & Mean \pm SD & $\mathbf{8 2 . 7 5} \pm 20.9$ \\
\hline IPSS PRE & Mean \pm SD & $\mathbf{2 6 . 1 2} \pm 3.67$ \\
\hline HB PRE & Mean \pm SD & $\mathbf{1 3 . 1 5} \pm \mathbf{1 . 7 5}$ \\
\hline HT pre & Mean \pm SD & $\mathbf{4 7 . 0 4} \pm 1.89$ \\
\hline NA pre & Mean \pm SD & $\mathbf{1 3 8 . 3 6} \pm \mathbf{1 . 9 2}$ \\
\hline
\end{tabular}

Table (3): Operative data distribution among studied group

\begin{tabular}{|l|l|l|}
\hline Operative time & Mean \pm SD & $47.5 \pm 7.03$ \\
\hline Pressure bladder & Mean \pm SD & $\mathbf{1 1 . 8 3} \pm \mathbf{2 . 4 6}$ \\
\hline Resected tissue & Mean \pm SD & $\mathbf{5 3 . 4 5} \pm \mathbf{9 . 3}$
\end{tabular}


Table (4):Catheter duration and hospital time distribution

\begin{tabular}{|l|l|l|}
\hline Catheter time & Mean \pm SD & $3.07 \pm 0.44$ \\
\hline Hospital time & Mean \pm SD & $\mathbf{2 . 3 8} \pm \mathbf{0 . 4 6}$ \\
\hline & \multicolumn{2}{l|}{} \\
\hline \multicolumn{2}{|l|}{ Table (5): Post-operative data distribution among studied group } & \\
\hline Prostate size post & Mean \pm SD & $34.7 \pm 7.3$ \\
\hline PVR volume post & Mean \pm SD & $\mathbf{1 8 . 7 9} \pm 7.27$ \\
\hline IPSS post 1 month & Mean \pm SD & $\mathbf{8 . 4 6} \pm \mathbf{2 . 5}$ \\
\hline IPSS post 3 month & Mean \pm SD & $\mathbf{3 . 5 5} \pm \mathbf{1 . 2}$ \\
\hline HB post & Mean \pm SD & $\mathbf{1 2 . 2 6} \pm \mathbf{2 . 6 2}$ \\
\hline HT post & Mean \pm SD & $\mathbf{4 6 . 4 1} \pm \mathbf{2 . 0 1}$ \\
\hline NA post & Mean \pm SD & $\mathbf{1 3 7 . 7 8} \pm \mathbf{1 . 9 9}$ \\
\hline
\end{tabular}

Table (6): Complication distribution among studied group

\begin{tabular}{|c|c|c|c|}
\hline & & $\mathrm{N}$ & $\%$ \\
\hline \multirow[t]{5}{*}{ Early } & No & 13 & 54.2 \\
\hline & Urinary Bladder clot & 3 & 12.5 \\
\hline & Hematuria & 3 & 12.5 \\
\hline & Urge Incontinence & 2 & 8.3 \\
\hline & UTI & 3 & 12.5 \\
\hline \multirow[t]{3}{*}{ Late } & No & 16 & 66.7 \\
\hline & Urge Incontinence & 1 & 4.1 \\
\hline & Retrograde ejaculation & 7 & 29.2 \\
\hline \multirow[t]{3}{*}{ End result } & Not & 16 & 66.7 \\
\hline & Complicated & 8 & 33.3 \\
\hline & Total & 24 & 100.0 \\
\hline
\end{tabular}

Table (7):Resection efficiency and Percentage of Resection to prostate size distribution among studied group

\begin{tabular}{|l|l|l|} 
& Resection efficiency & $\begin{array}{l}\text { Percentage of Resection to } \\
\text { prostate size }\end{array}$ \\
\hline Mean+ SD & $\mathbf{1 . 1 4 \pm 0 . 2 3}$ & $\mathbf{0 . 6 0 \pm 0 . 0 8}$
\end{tabular}

\section{DISCUSSION}

This study was done in urology department of zagazig hospital university in period between January 2018 to December 2018 on 24 patient with BPH scheduled for surgical management for TURP we are using the suprapubic cystostomy during monopolar transurethral resection of large prostate $>80$ gram, and follow up the patient to ensure the method was more safe and more effective.

Despite advance and available continuous flow resectoscope still TUR syndrome is challenge facing of endo urologist when resecting large prostate > 80gram .
In the current and new studies were comparing both techniques (suprapubic cystostomy versus non suprapubic cystostomy during monopolar transurethral resection of prostate) as techniques of Prostatectomy and we are taking the advantages and disadvantages of both technique.

In our study the mean age( 64.95 \pm 4.43 ) and mean prostatic size was (88.87 \pm 7.5 ), which similar to the study of Konrad et al.[5] , who found the mean age ( 69.4 \pm 6.3 ) and the mean prostatic size $(100.2 \pm 23.1)$ and the study of Guo et al.[3], who found the mean age $(70.0 \pm 7.2)$ and mean prostatic size was $(116.2 \pm 30.2)$ 
In our study we found the surgical time was $(47.5 \pm 7.03)$ measured from started the resection to the folly catheter inserted. While, the study of Guo et al.[3], who reported that the surgical time was $(81.09 \pm 34.38)$ due to the mean prostatic size was bigger.

Another study by Konrad et al.[5], found that the surgical time was $(82.6 \pm 37.0)$ because the mean prostatic size was bigger.

In our study the mean catheter time removed was( $2.37 \pm 0.44)$ day and post oprative hospital stay was $(2.38 \pm 0.46)$, which similar to the study of Konrad et al.[5], who reported that the mean catheter time removed was ( 2.08 ) day and mean post oprative hospital stay was(3.27 \pm 3.1$)$ day which smaller than the study of Guo et al.[5], who reported that the mean catheter time removed was (4.6 ) day and mean post oprative hospital stay was $(6.0 \pm 3.1)$ due to more complicated cases.

In our study the mean prostatic resected tissue weight was (53.45 \pm 9.3$)$ and mean Percentage of Resection to prostate size $(0.60 \pm 0.08)$, which similar to our study Konrad et al. .[5], who found that the mean prostatic resected tissue weight was( $54.35 \pm 0.08$ ) and mean Percentage of Resection to prostate size (0.54)

In our study we found the mean resection efficiency was $(1.14 \pm 0.23) \mathrm{g} / \mathrm{mint}$ while Hung et al., .[6] reported that the mean resection efficiency was $(0.75 \pm 0.22) \mathrm{g} / \mathrm{mint}$, and Konrad et al. .[5], who found the mean Resection efficiency was( $0.65 \pm 0.20) \mathrm{g} / \mathrm{mint}$

In our study the mean bladder pressure was $(11.83 \pm 0.44) \mathrm{cmH} 2$ Konrad et al. [5] that found bladder pressure (1418) $\mathrm{cmH} 2 \mathrm{O}$, while in the study of Hung et al., [6], it was $(20.5 \pm 5.5) \mathrm{cmH} 2 \mathrm{O}$; this was higher value may be due to the use one flow resectoscop and small gauge of catheter in their study.

In our study we found the mean PVR volume (18.79 \pm 7.27$)$, IPSS (3.55 \pm 1.2$), \mathrm{HB} \&$ HT were $(12.26 \pm 2.62) \mathrm{g} / \mathrm{dl} \&(46.41 \pm 2.01) \%$ respectively and sodium in pre $(137.58 \pm 1.99) \mathrm{ml} / \mathrm{dl}$ which are within normal and nearness to Guo et al. [3] and Konrad et al. [3].
In our study the complication were attribute to the clavien score modified for TURP we found (13 cases) without any early complication while (3cases) had blood clot, hematuria , UTI for each (Clavien I) managed by culture and sensitivity and started empirical antibiotics until results were obtained. early Blood clot and hematuria managed by continues saline irrigation and clot evacuation until urine became clear and urine incontinence in ( 3 cases) managed by Anticholinergic drug, while Guo et al. [3] , reported blood clot in (2 cases), hematuria in (13 cases), UTI in (8 cases) and urine incontinence in (1 cases) managed by same our protocol

In Konrad et al. [5] they report the complications were attributed to the Clavien score modified for TUR-P was (23 cases) (Clavien I) and 10 cases (Clavien II). Which worse than our results. This may be due to the large sample size of these studies and their long period of follow up.

Comparing our method of suprapubic catheter cystostomy during monopolar transurethral resection of large size prostate to their near of the above studies, our results would be acceptable.

Statistical data analysis in our study showed positive significant differences regards the resection efficacy and percentage of resected tissue when compared with previous studies used monopolare transurethral resection of large size prostate without suprapubic cystostomy .

However, there were some limitations such as the small sample size and the short follow up period that was not sufficient to compare the our procedure efficiently.

\section{CONCLUSION}

The using of suprapubic cystostomy during monopolar transurethral resection of large prostate $>80$ gram, is more safe and more effective method.

Declaration of interest

The authors report no conflicts of interest. The authors alone are responsible for the content and writing of the paper.

Funding information

None declared 


\section{REFERENCES}

1. Sarma AV, Jacobson DJ, McGree ME, et al (2005): A population based study of incidence and treatment of benign prostatic hyperplasia among residents of Olmsted County, Minnesota: 1987 to 1997. J Urol; 173:204853.Eisner BH, Goldfarb DS, Pareek G. Pharmacologic treatment of kidney stone disease. Urol Clin North Am. 2013;40:21-30.

2. Reich O, Gratzke C, Bachmann A et al (2008) Morbidity, mortal-ity and early outcome of transurethral resection of the prostate: a prospective multicenter evaluation of 10,654 patients. J Urol 180:246-249. http s://doi.org/10.1016/j.juro .2008.03.058

3. Guo R, Yu W, Zhang $K$ and $X u \quad B$ (2016): Impact of changing trends in medical therapy on transurethral resection of the prostate: two decades of change in China. Urology; 92: 80-
4. Fujiwara A, Nakahira J, Sawai T, Inamoto T, Minami T. Prediction of clinical manifestations of transurethral resection syndrome by preoperative ultrasonographic estimation of prostate weight. BMC Urol2014; 14: 67-72

5- Konrad W, Cazana I, Schoenthaler M, Katzenwadel A, Spaeth J and Miernik A (2018): Low-pressure monopolar electroresection of the prostate for glands sized $>70$ vs. $<70 \mathrm{cc}$ performed with continuous irrigation and suprapubic suction: perioperative and long-term outcome. World $\mathbf{J}$ Urol.; 36 (3) : 449-457.

6- Hung JS, Yung CC, Chun JH, Yu HS, Jong MH and SY (2007) : Catheter-Assisted Transurethral Resection of the Prostate: Is It Better than the Bipolar Electroresection Method Department of Urology, Mackay Memorial Hospital, 92 Chungshan North Rd., Sec. 2, Taipei, Taiwan 104, R.O.C

To Cite This Article: Elfayomy AE, Abd Elsamad KM ${ }^{(1)}$, Desoky EA \& forgani AE. Impact Of Using Suprapubic Cystostomy During Monopolar Transurethral Resection Of Large Size Prostate: A Prospective Study.ZUMJ 2019;25(5);767-772. DOi: 10.21608/zumj.2019.10200.10850. 